\title{
In need of a reality check
}

\section{To the Editor:}

I am writing in response to your editorial entitled "In need of counseling?" ${ }^{\text {, in }}$ which you argue that direct-to-consumer (DTC) companies should not be shackled by regulation and that physicians cannot continue to be gatekeepers of genetic information. As a healthcare provider on the front lines of genomic medicine and founder of Helix Health (Stamford, Connecticut, USA) - a company that provides medically validated genetic technology to patients-I believe the editorial contains several incorrect assumptions and fails to reflect the reality of the current situation.

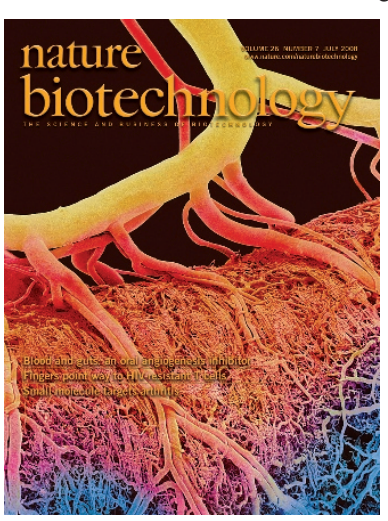

results? Could we give her medical advice over the phone if she was in a state in which we were not medically licensed? Will our malpractice coverage protect us?

The thoughts of simple patient care blur into lines of regulation and medicolegal liability. But this is nothing new. Physicians have been trying to provide the best care with the earliest detection for centuries, yet only in the past century have we been encumbered by significant laws and the heavy-handed regulation to which you refer in your editorial. These regulations have been drawn up to help repair trust in the medical system. In the early part of

At Helix Health, we have struggled with how we may best use technologies such as DTC single-nucleotide polymorphism (SNP) chips and soon-to-be-complete genomic scans. Almost weekly, we get requests from patients regarding some DTC genetic tests they have taken and what they should do with their results. They call us asking for medical advice.

Recently, a patient called our practice asking about results from a very popular direct-to-consumer SNP scan company. She told us that she had downloaded her report, ran it through Promethease software (which generates reports from SNP data) and come up with some disturbing results in her cytochrome P450 system. The patient had spent hours researching and trying to find answers, only to come up with terminology she couldn't understand and didn't have the time to learn. So she turned to her trusted source of medical information: her primary care physician. According to her report, the physician had shrugged his shoulders; so, in a search for the answers, she was pointed in our direction by someone at Genentech (South San Francisco, California, USA).

Helix Health sees patients on a weekly basis who have issues with genetics and their medications. We evaluate these patients and provide medical care on the best evidencebased guidelines we have; sometimes, we take the data and synthesize our own-all with the primary directive of primum non nocere (first do no harm).

But what if there were nothing we could change? What if the advice we gave had no evidence behind it? What if on that phone call, the patient was asking about $9 \mathrm{p} 21.3$ the twentieth century, when healthcare lacked regulation, there were many cases where, under the guise of healthcare, patients were exposed to quackery and unethical research resulting in significant harm.

Despite professing to do so, companies and practitioners could not police themselves then, and neither can they do so now. Without regulatory oversight backed by law, our chain of trust with the patient would be broken. What good is progress without safety and trust? Perhaps regulation has slowed the pace of progress in medical care, but the health system we have today is much more safe and trustworthy than it was a century ago.

The addition of DTC genomic testing to healthcare and the drive for patient-centered care have done nothing to alleviate these issues of trust or safety. In fact, by asking for less regulation, we may soon deconstruct public trust and safety even further. A report by the investment bank Burrill \& Company (San Francisco) published last $J_{u n e^{2}}$ reveals that patients choose one place over all others to obtain health and genetic information: their physician. They do this despite a frustration with a system plagued with decreasing valuation of professionals' time and demands to do more and more with less and less-not to mention in shorter and shorter appointment times.

As demonstrated by the patient who called us with a Promethease report, as alternative means for patients to access and interpret their own biometrics become available, the burden of the traditional health provider will be transferred squarely onto patients. It will be up to patients to sift through reams of information and come up with their own, nonprofessional conclusions.

Of course, such a system may have advantages to an educated patient, but this shift assumes that the patient, when scouring the internet for information, can do the following: (i) find a reliable source of information; (ii) understand the language at such a level that they will come to an educated conclusion; (iii) discover evidence showing whether this intervention may be beneficial or harmful; and (iv) use this information to properly implement the intervention.

Certainly, some automated systems have been designed to help patients interpret tests without the assistance of a physician (e.g., Genelux's software GENEMEDRX for PGx testing or for regular tests $<$ http://www.globalrph.com/ labinter.htm $>$ ). This is often the case with tests that reveal yes-or-no answers. But this is not the case for our genome or for current genetic tests. Even validated genetic tests, such as $B R C A 1$ or $B R C A 2$ testing, may result in at least three, if not four, answers. I always tell patients that the results could be "yes," "no," "maybe" or "we don't know." How can we expect our telephone patient to navigate such a realm by herself without any wherewithal to know whether to trust the information that she finds?

At present, there are several peer-reviewed websites filled with health information. Unfortunately, this serves no use to most people in a citizenry that is woefully health illiterate. The information on genomic healthcare is even less reviewed and people even less literate. This results in pitting patients against overexuberant reports of scientific discovery that may not have clinical relevance. In such cases, it is the physician who can serve as the proxy, buffering the information and helping guide patients.

Physicians have the training to interpret blood pressures, HIV tests and pregnancy kits. They have studied and speak the language of medicine fluently. They are the best means of interpreting genetic test information for patients. And they have informed patient decision-making for centuries with the primary directive being primum non nocere. Unfortunately, the web has taken no such oath.

COMPETING INTERESTS STATEMENT

The author declares competing financial interests: details accompany the full-text HTML version of the paper at http://www.nature.com/naturebiotechnology/.

\section{Steven Murphy}

Helix Health, Stamford, Connecticut, USA. e-mail: steven.murphy@helixhealth.org

1. Anonymous. Nat. Biotechnol. 26, 716 (2008).

2. <http://www.burrillandco.com/content CWSurvey_61708.pdf>. 